NASA

Contractor Report 185136
AVSCOM

Technical Report 89-C-015

\title{
Efficient Numerical Method for Computation of Thermohydrodynamics of Laminar Lubricating Films
}

Harold G. Elrod

Old Saybrook, Connecticut

August 1989

Prepared for

Lewis Research Center

Under Purchase Order C-22406-M

\section{N/Sก \\ National Aeronautics and \\ Space Administration}

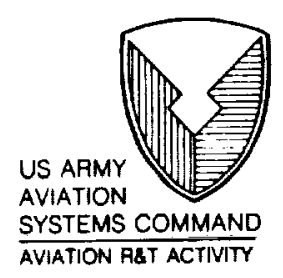




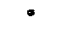

.

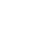




\title{
Efficient Numerical Method for Computation of Thermohydrodynamics of Laminar Lubricating Films
}

\author{
Prof. Harold G. Elrod \\ 14 Cromwell Court \\ old Saybrook, CT 06475
}

\section{Summary}

The purpose of this paper is to describe an accurate, yet economical, method for computing temperature effects in laminar lubricating films in two dimensions. The procedure presented here is a sequel to one presented in Leeds in 1986 that was carried out for the one-dimensional case.

Because of the marked dependence of lubricant viscosity on temperature, the effect of viscosity variation both across and along a lubricating film can dwarf other deviations from "ideal" constant-property lubrication.

In practice, a thermohydrodynamics program will involve simultaneous solution of the film lubrication problem, together with heat conduction in a solid, complex structure. The extent of computation required makes economy in numerical processing of utmost importance. In pursuit of such economy, we here use techniques similar to those for Gaussian quadrature. We show that, for many purposes, the use of just two properly positioned temperatures (Lobatto points) characterizes well the transverse temperature distribution. 


\section{INTRODUCTION:}

The purpose of this paper is to describe an accurate, yet economical, method for computing temperature effects in laminar lubricating films. The procedure presented here is a sequel to one presented in Leeds in $1986 .{ }^{1}$

Because of the marked dependence of lubricant viscosity on temperature, the effect of viscosity variation both across and along a lubricating film can dwarf other deviations from "ideal" constant-property lubrication. In two recent papers 2,3 Khonsari has summarized the growing literature concerned with the present subject. Consequently, we shall not undertake a survey here, but refer only to those articles used for support or comparisons.

In practice, a thermohydrodynamics program will involve simultaneous solution of the film lubrication problem, together with heat conduction in a solid, complex structure. The extent of computation required makes economy in numerical processing of utmost importance. In pursuit of such economy, we here use techniques similar to those for Gaussian quadrature. We show that, for many purposes, the use of just two properly positioned temperatures characterizes well the transverse temperature distribution.

\section{NOMENCLATURE}

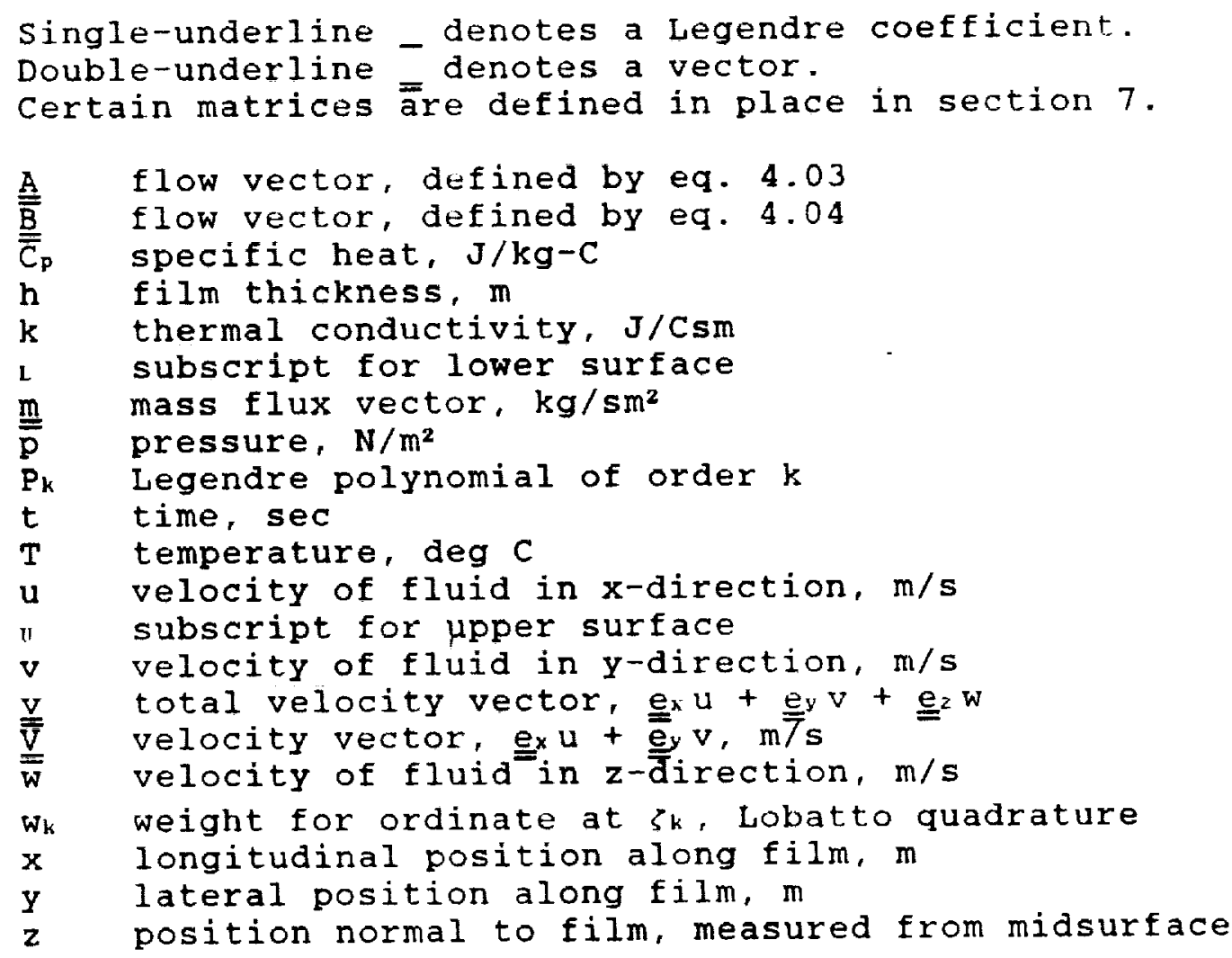


$\Phi$ dissipation, $\mathrm{J} / \mathrm{sm}^{3}$, defined by eq. 4.03

$\mu \quad$ viscosity, $\mathrm{Ns} / \mathrm{m}^{2}$

$\xi \quad$ fluidity $=1 / \mu, \mathrm{m}^{2} / \mathrm{Ns}$

$\zeta \quad 2 z / h$, fractional transverse position

p density, $\mathrm{kg} / \mathrm{m}^{3}$

\section{LOBATTO INTERPOLATION AND QUADRATURE:}

In general terms, the problem to be treated is one of threedimensional heat convection. A numerical solution is effected by sampling the velocities, pressure and temperature over a chosen grid of points, and interlinking their values by algorithms that incorporate appropriate physical laws. Generally speaking, the fewer sample points required, the less the computational effort. Consequently, we ask: "What are the best cross-film sampling positions?" The answer is provided by the theory of orthogonal polynomials.4,5

Figure 1 shows a section of lubricating film, with the normal displacement, $\zeta$. scaled to be -1 on the lower wall, and +1 on the upper. At certain locations, $\zeta \mathrm{k}$, we intend to obtain sample values of the flow variables and to deduce therefrom certain intermediate cross-film values, derivatives and integrals. For illustrative purposes, consider the temperatures $T_{k}=T(\zeta k)$. These are assumed to be knowr at $\zeta=1$ and $\zeta=-1$, and at $N$ intermediate points.

If the intermediate sample points are equispaced, and a polynomial for $T(\zeta)$ is passed through them. the excursions of such a polynomial between points can become unacceptably large. See, for example, Fig. 2, where a tenth-degree polynomial is used to approximate the stepfunction $T(\zeta<0)=1 ; T(\zeta>0)=0$ by collocation at eleven equispaced points. On the other hand, if a tenth-degree polynomial is collocated at the endpoints $(\zeta=-1 ; \zeta=1)$ and at the zeroes $(\zeta k)$ of the Jacobi polynomial(a) $\mathrm{P}_{8} \mathrm{l}_{\text {l }}(\zeta)$ ("Lobatto points"), conformity to the step function is much better. Indeed, if the order of the polynomial is increased, equispace interpolation may fail to converge at all, whereas the latter form of interpolation becomes progressively better.

Not only do the Lobatto points serve well for interpolation by high-order polynomials, but they also serve for accurate numerical integration ${ }^{5}$. It $c$ an be shown that $N$ such internallyselected points permit exact numerical integration of a polynomial of order $2 \mathrm{~N}+1$ over the range $-1<\zeta<1$. Thus:

(a) For $\mathrm{N}$ interior points, the Lobatto locations ( $\zeta$ ) are at the zeroes of $\mathrm{dP}_{\mathrm{N}+1}(\zeta) / \mathrm{d} \zeta=\mathrm{N}(\mathrm{N}+1) \mathrm{P}_{\mathrm{N}-1} 1 \cdot 1(\zeta)$, where $\mathrm{P}_{\mathrm{N}}(\zeta)$ is the Legendre polynomial of order $\mathrm{N}$. 


$$
\left[2.01 \int_{-1}^{1} \int^{T}(\zeta) d \zeta=\sum w_{k} T_{k}\right.
$$

The Lobatto locations, $\zeta_{k}$, and weight factors, $\mathbf{w k}_{k}$, are to be found

\begin{tabular}{|c|c|}
\hline Location & Weight \\
\hline $\begin{array}{c}-1 \\
-1 / \sqrt{5} \\
1 / \sqrt{5} \\
1\end{array}$ & $\begin{array}{l}1 / 6 \\
5 / 6 \\
5 / 6 \\
1 / 6\end{array}$ \\
\hline
\end{tabular}
in Abramowitz and steguf6. For $\mathrm{N}=2$, we have:

Note that, in contrast to Gaussian quadrature, Lobatto's technique incorporates endpoint values which, in our case, are known, and might as well be used.

The approach taken in this paper is to form partial differential equations in $x, y$ for the Lobatto-point temperatures, with the transverse temperature distribution given by a collocated polynomial. The "fluidity", $\xi=1 / \mu$ is also collocated to its Lobatto-point values, $\xi_{k}=\xi\left(T_{k}\right)$.

Let us turn now to the analytical development which incorporates these ideas.

\section{BASIC THERMOHYDRODYNAMIC EQUATIONS:}

The equations to be used are for laminar lubrication with a fluid possessing constant density and constant thermal properties. The momentum equation is:

$[4.01](\partial / \partial z)(\mu \partial \underline{\underline{y}} / \partial z)=7 p$

the pressure being independent of "z".

And the energy equation is:

[4.02] $\rho C_{p}(D T / D t)=k\left(\partial^{2} T / \partial z^{2}\right)+\Phi$ with:

$[4.03] \Phi=\mu(\partial \underline{\underline{v}} / \partial z)^{2}$

Here the viscosity, $\mu$, may depend markedly on the local temperature $T$. In addition, the conservation of mass (or volume) must be satisfied; i. e.,

$$
[4.04] \nabla \cdot \mathrm{v}=0
$$

Several investigators ${ }^{7,8}$ have justified the use of these equations by showing that the effects of variations in density, specific heat, etc.. of the lubricant are quite secondary to those resulting from changes in its viscosity, which usually varies substantially with temperature. 
The boundary conditions to be satisfied by eqs. [4.01 - 4.03] are as follows. The liquid velocities must conform to the upper and lower surface motions, and the liquid temperature to the surface temperatures. At the film peripheries, incoming liquid temperatures correspond to ambient conditions, whereas outgoing temperatures derive from the interior where they originate.

\section{VELOCITIES. REYNOLDS EQUATION :}

To compute the velocities, it is, for several reasons, convenient to use the fluidity expressed as a series in Legendre polynomials. Thus:

$$
[5.01] \xi=\sum \xi_{k} P_{k}(\zeta)
$$

As previously stated, the coefficients $\xi_{-}$are here determined by collocation of the fluidity at the Lobatto points, where its values are determined by the $T_{k}$. A double integration of eq. [5.01] then yields for $\underline{\underline{V}}=\underline{\underline{e}} \mathrm{u}+\underline{\underline{\underline{e}}} \mathrm{v}$.

$$
\text { [5.02] } \quad \underline{\underline{v}}=\underline{\underline{V}}_{1}+\underline{A}_{-1} \int \zeta d \zeta+\underline{\underline{B}}_{-1} \int \zeta \xi \mathrm{d} \zeta
$$

where:

$$
\begin{aligned}
& 11 \\
& {[5.03] \quad \underline{\underline{A}}=\left[\underline{\underline{V}}_{1}-\underline{\underline{V}}_{1}-\underline{\underline{B}} \underset{-1}{\left.\int \zeta \xi \mathrm{d} \zeta\right] /\left[\int \zeta \mathrm{d} \zeta\right]} \underset{-1}{\underline{a}}\right.}
\end{aligned}
$$

and :

$$
[5.04] \underline{\underline{B}}=(h / 2)^{2} \nabla p
$$

To obtain the lineal mass flux, eq. [5.02] must be integrated again. The result is:

$$
[5.05] \underline{\underline{m}} / \rho=\left(\underline{\underline{V}}_{0}+\underline{\underline{V}}_{\mathrm{L}}\right)(\mathrm{h} / 2)-(\mathrm{h} / 3) \underline{\xi}_{1} \underline{\underline{\mathrm{A}}}-(2 / 3) \underline{\underline{\mathrm{B}}}\left(\xi_{0}+2 \xi_{2} / 5\right)
$$

This result is independent of the number of terms in the series [5.01]. When it is inserted into the mass continuity equation:

[5.06] $\partial \mathrm{h} / \partial t+\nabla \cdot(\underline{\underline{m}} / \rho)=0$

the following generalized Reynolds equation results:

$[5.07] \nabla \cdot \xi_{\rho} h^{3} \nabla p=6\left(\underline{\underline{V}}_{0}+\underline{\underline{V}}_{L}\right) \cdot \nabla h+12(\partial \mathrm{h} / \partial t)-2 \nabla \cdot\left(\xi_{1} / \xi_{0}\right) h\left(\underline{\underline{V}}_{0}-\underline{\underline{V}}_{1}\right)$

where:

$$
[5.08] \xi_{p}=\xi_{0}+0.4 \xi_{2}-\left(\xi_{3}\right)^{2} /\left(3 \xi_{0}\right)
$$

In form, eq. [5.07] differs from the standard Reynolds equation ${ }^{9}$ only through its last term. 
Now we wish to express our differential equations using the fractional gap position as transverse coordinate across the film. Thus :

$[5.09] \zeta=2 z / h$

where " $z$ " is measured from the midsurface. Taking " $x$ " as a typical lateral coordinate and "u" as a typical variable, we note that:

$[5.10](\partial u / \partial x)_{y, z}=(\partial u / \partial y)_{y, \zeta}-\zeta(\partial \log (h) / \partial x)_{y}(\partial u / \partial \zeta)_{x, y}$ via:

The transverse velocity, $w$, can be found from mass continuity

[5.11] $\partial w / \partial z=-(\partial u / \partial x+\partial v / \partial y)=-(\nabla \cdot \underline{\underline{v}})_{z}$

But :

$[5.12](\nabla \cdot \underline{\underline{V}})_{2}=(\nabla \cdot \underline{\underline{V}})_{\zeta}-\zeta \nabla \log (\mathrm{h}) \cdot(\partial \underline{\underline{V}} / \partial \zeta)$

Substituting [5.12] into [5.11] and integrating, we get:

[5.13] $\quad \mathrm{w}=\mathrm{W}_{\mathrm{L}}-\int_{-\mathrm{h} / 2}^{\mathrm{z}}(\nabla \zeta \cdot \underline{\mathrm{V}}-\zeta \nabla \log (\mathrm{h}) \cdot(\partial \underline{\underline{\mathrm{V}}} / \partial \zeta) \mid \mathrm{dz}$

Integration by parts gives:

$[5.14] \mathrm{W}=\mathrm{WL}_{\mathrm{L}}+\underline{\underline{V_{1}}} \cdot \nabla(\mathrm{h} / 2)+\zeta \underline{\underline{\mathrm{V}}} \cdot \nabla(\mathrm{h} / 2)-\nabla \zeta \cdot[(\mathrm{h} / 2) \zeta \underline{\zeta} \underline{\underline{\mathrm{V}} \mathrm{d} \zeta]}$

\section{TEMPERATURE EQUATION:}

To obtain a convenient differential equation for the temperature, we rewrite eq. [4.02] as:

$[6.01]$

$\partial \mathrm{T} / \partial t+\mathrm{u}(\partial \mathrm{T} / \partial \mathrm{x})_{y \cdot \zeta}+\mathrm{v}(\partial \mathrm{T} / \partial \mathrm{Y})_{\mathrm{x}, \zeta}+(2 / \mathrm{h})(\partial \mathrm{T} / \partial \zeta)_{x, y}(\mathrm{w}-\zeta \mathrm{V} \cdot \nabla(\mathrm{h} / 2))=$

$$
\left(4 k / h^{2}\right)\left(\partial^{2} T / \partial \zeta^{2}\right)_{x, y}+\Phi /\left(\rho C_{p}\right)
$$

To treat the cross-velocity term, we note that kinematics gives:

$[6.02] \mathrm{w}_{\mathrm{L}}+\underline{\underline{\mathrm{V}}} \nabla(\mathrm{h} / 2)=-\partial(\mathrm{h} / 2) / \partial \mathrm{t}$

substituting $[5.14]$ and [6.02] into [6.01], we get:

$$
\begin{gathered}
{[6.03] \partial \mathrm{T} / \partial \mathrm{t}+\underline{\underline{V}} \nabla \mathrm{T}-(1 / \mathrm{h})(\partial \mathrm{T} / \partial \zeta)\left[(1+\zeta)(\partial \mathrm{h} / \partial t)+\nabla \cdot \mathrm{h} \int \underline{\mathrm{V}} \mathrm{d} \zeta\right]=} \\
\left(4 \mathrm{~K} / \mathrm{h}^{2}\right)\left(\partial^{2} \mathrm{~T} / \partial \zeta^{2}\right)+\Phi /\left(\rho \mathrm{C}_{\mathrm{p}}\right)
\end{gathered}
$$


All partial derivatives in the foregoing equation are in $x, y, \zeta, t$ space. There is one such partial differential equation [6.03] in $x, y, t$ for each $T_{k}$.

\section{NUMERICAL PROCEDURES :}

It is convenient to treat the $T_{k}\left(X_{1}, Y_{j}\right), \xi_{k}\left(X_{1}, y_{j}\right)$ as vector matrices, and to use matrix notation. We have:

$[7.01] \quad T(\zeta)=\sum \underline{T}_{n} \quad P_{\text {i }}(\zeta)$

$[7.02] \quad \xi(\zeta)=\sum_{2} \mathrm{P} \quad \mathrm{P}_{\mathrm{u}}(\zeta)$

Therefore:

[7.02] $\mathrm{T}_{k}=\sum \underline{\mathrm{T}}_{\mathfrak{n}} \mathrm{P}_{\mathrm{a}}\left(\zeta_{k}\right)$ or: $\mathrm{T}_{k}=\sum C_{k} \mathrm{a} \underline{T}_{k}$ or: $\mathrm{T}=C \underline{T}$ and: $\underline{T}=C^{-1} \mathrm{~T}$

Also, then:

$[7.03] \xi=C \xi$ and $: \xi=C^{-1} \xi$

Successive differentiation of [7.01] enables us to write:

[7.03] $\partial \mathrm{T} / \partial \zeta=\mathrm{DT}$ and: $\partial^{2} \mathrm{~T} / \partial \zeta^{2}=\mathrm{ET}$

Successive integration of [7.02] permits us to write

$[7.04] \quad \underline{\underline{V}}=\underline{\underline{V_{1}}}+\underline{\underline{A}} \xi \xi+\underline{\underline{B}} \xi \xi$ and $:$

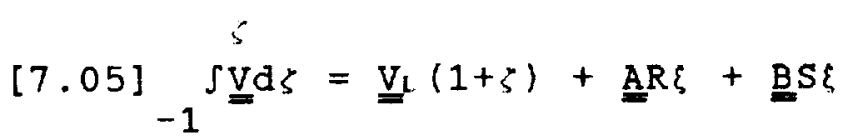

To preserve numerical stability, backward differences are used for the convective terms. Thus, at the point (i,j) we write:

$[7.06] \mathrm{u}(\partial \mathrm{T} / \partial \mathrm{x})=\operatorname{abs}\left(u_{1}, \jmath\right)\left[T_{1}, \jmath-T_{1}-g x, J\right] ; g x=\operatorname{sgn}\left(u_{i}, \downarrow\right)$

with a similar expression for $v(\partial T / \partial y)$.

Now form the diagonal matrix, Ed, from the diagonal terms of $E$, and let $E_{o}=E-E_{1}$. With these definitions, the matrix finitedifference equation corresponding to [6.03] is:

[7.07] $\left[1 / \Delta t+a b s(u) / \Delta x+a b s(v) / \Delta Y-\left(4 k / h^{2}\right) E_{d}\right] T^{n e w_{1}, j}=$

$T_{1, j} / \Delta t+\left|a b s(u) T_{1-g x, j}\right| / \Delta x+\left|a b s(v) T_{1, j-g y}\right| / \Delta y+\left(4 k / h^{2}\right) E_{0} T_{1, j}+$ $(1 / \mathrm{h})\left(\nabla \cdot \mathrm{h} \int \underline{\underline{\mathrm{V}}} \zeta\right) \mathrm{D} \mathrm{T}_{1}, \mathrm{~J}+\Phi / \mu \mathrm{C}_{\mathrm{p}}$ 
Here $T^{n e w}$ denotes $T(t+\Delta t), u, v, \Phi$ and $T$ belong to the same transverse row $(\zeta k)$, and the integral of velocity is from the lower wall to $\zeta k$.

The explicit form of the difference equation [7.07] is stable for a large $\Delta t$, such as was used to generate the steady-state results presented in this report.

\section{COMPUTATIONAL RESULTS:}

Validation of the computer program was attempted in various ways. Comparisons were made with the one-dimensional calculations of Hunter and zienkiewicz'10, Dowson and Hudson ${ }^{7}$ and of Hahn and Kettleborough", who all used the physical properties tabulated below.

$$
\begin{aligned}
& \mu=0.13885 \exp \left(-\beta\left(T-T_{a m b i e n t}\right)\right), N s / \mathrm{m}^{2} ; \beta=0.045 \\
& \rho C_{p}=1.7577 \mathrm{~J} / \mathrm{m}^{3} \mathrm{C} \\
& k=7.306 \mathrm{E}-08 \mathrm{~m}^{2} / \mathrm{s} \\
& T_{a m b i e n t}=0 \text { (used as reference, only) }
\end{aligned}
$$

These same properties are used for all examples of this report, except that $\beta=0$, instead of 0.045 , for the constant-property calculations.

Dowson and Hudson chose the following bearing characteristics.

$$
\begin{aligned}
& \mathrm{L}=0.18288 \mathrm{~m} ; \mathrm{W} \text { infinite } \\
& \mathrm{U}_{U}=31.96 \mathrm{~m} / \mathrm{s} ; \mathrm{U}_{1}=0 \\
& \mathrm{~h}_{1}=1.8288 \text { E-04 m; } \mathrm{h}_{2}=0.9144 \text { E-04m }
\end{aligned}
$$

Figures 3 and 4 compare our results with theirs(b). Agreement is certainly satisfactory, though not perfect. Dowson and Hudson used $\Delta \mathrm{x}=\mathrm{L} / 20$ and a constant $\Delta \mathrm{y}=\mathrm{h}_{2} / 20$, whereas we employed $\Delta \mathrm{x}=\mathrm{L} / 30$ and $N=8$. In these comparisons, as in others made, the reasons for the observed small discrepancies are difficult to assign. Therefore, it was decided to write the present program for arbitrary $N$, and to use $\mathbf{N}=8$ as a standard against which to test more approximate, but faster versions employing $\mathbf{N}=2$ or 3 . To assist others

(b) All dotted curves, except those in Fig. 2, were collocated at the Lobatto points, and interpolated with an auxiliary plotting program; $i . e$. the dotted curves are not everywhere in complete agreement with the corresponding Legendre polynomial expansions. 
who may wish to make comparisons with their own programs, we list some results for the above problem in the Appendix.

In Fig. 3, the great reduction in load capacity due to lubricant warmup is manifest. Of course, in engineering design practice some allowance for this effect is made by assigning some lowered constant viscosity corresponding to an estimated temperature rise.

Figure 4 shows the convergence with $N$ of results obtained using the present program. There is no perceptible difference between the results for $N=5$ and those for $N=8$. Somewhat fortuitously, the results for $N=2$ also almost coincide with the "true" curve. Figure 5 shows the convergence of the temperature distributions. The Lobatto-point results for $N=2$ and $N=3$ are compared with the curves for $N=8$ at the bearing exit, and at the halfway point.

Reverse convection has been a source of difficulty for some investigators. Accordingly, we show in Figs. 6 and 7 some calculations for a high film-thickness ratio of 4 . Note the rapid variation of temperature in the bearing inlet --- incoming temperatures are taken at an entrance value of 0 , whereas temperatures in the backflow region originate from a region where viscous heating has occurred. As shown in Fig. 1, Lobatto interpolation is particularly suited to cope with such variation. The two-temperature version ( $N=2$ ) of our program performs surprisingly well.

All of the foregoing calculations are for a one-dimensional bearing, run with the program, however, as a two-dimensional wide bearing. The same cases were also solved earlier by a one-dimensional procedure ${ }^{1}$ enbodying Lobatto-point methods. But when extended to two-dimensional problems, that earlier procedure proved to be persistently unstable. To deal successfully with the added dimension, the present method was devised. Figures 8,9 and 10 show some sample "true" two-dimensional results obtained with a square slider bearing.

We intend to continue this investigation by engaging in some parametric studies and by coupling the new technique to:

inlet-groove temperature distribution cavitation

heat conduction in the bearing body

\section{ACKNOWLEDGMENT :}

It is a pleasure to acknowledge the encouragement and assistance of David Brewe, USAAVSCOM, in this modification and extension of our earlier, joint study. 


\section{APPENDIX :}

PRESSURE DISTRIBUTION FOR DOWSON-HUDSON PROBLEM

$\begin{array}{ll}\frac{\mathrm{x} / \mathrm{L}}{0} & \text { pressure, } \mathrm{N} / \mathrm{m}^{2} \\ .1 & 0 \\ .2 & 3545479 \\ .3 & 6434485 \\ .4 & 8755968 \\ .5 & 1.051984 \mathrm{E}+07 \\ .6 & 1.167347 \mathrm{E}+07 \\ .7 & 1.209784 \mathrm{E}+07 \\ .8 & 1.158809 \mathrm{E}+07 \\ .9 & 9815331 \\ 1 & 6259130\end{array}$

TEMPERATURES OBTAINED FOR DOWSON-HUDSON PROBLEM

\begin{tabular}{|c|c|c|c|c|c|c|}
\hline & & & & $\mathrm{K} / \mathrm{L}$ & & \\
\hline$\zeta$ & $\underline{0}$ & 0.2 & 0.4 & 0.6 & 0.8 & 1.0 \\
\hline & 0 & 0 & 0 & 0 & 0 & 0 \\
\hline .9195339 & 0 & 1.883201 & 3.275796 & 4.859227 & 6.956678 & 9.435757 \\
\hline 7387739 & 0 & 5.325756 & 9.360686 & 13.81515 & 6049 & 26.13743 \\
\hline 4779249 & 0 & 7.951722 & 14.41125 & 21.01087 & 318 & 36.01018 \\
\hline 165279 & 0 & 8.313656 & 15.44364 & 21.92048 & 27.68786 & 31.61222 \\
\hline 165279 & 0 & 7.881326 & 14.21572 & 19.14167 & 22.08036 & 22.90305 \\
\hline 79249 & 0 & 7.5885 & 12.91233 & 15.74303 & 16.07165 & 15.18215 \\
\hline 87739 & 0 & 6.967654 & 10.07563 & 10.47426 & 9.308805 & 8.233334 \\
\hline 5270 & 0 & 3.865244 & 4.300633 & 3.853627 & 3.094525 & 2.774959 \\
\hline 1 & 0 & 0 & 0 & 0 & 0 & 0 \\
\hline
\end{tabular}

\section{REFERENCES :}

1. "Thermohydrodynamic analysis for laminar lubricating films". H. G. Elrod and D. E. Brewe, Leeds-Lyon Symposium on Tribology, Leeds, UK, Sept. 8-12, 1986.

2. Khonsari, M. M. "A Review of Thermal Effects in Hydrodynamic Bearings. Part I: Slider and Thrust Bearings," Trans. ASLE, 1986.

3. Khonsari, M. M., "A Review of Thermal Effects in Hydrodynamic Bearings. Part II: Journal Bearings," Trans. ASLE, 1986. 
4. Lanczos, Cornelius, "Applied Analysis", Dover Publications, New York, 1988, p. 371 .

5. Villadsen, John, \& Michelsen, M. L., "Solution of Differential Equation Models by Polynomial Approximation," Prentice-Hall, Inc. Englewood Cliffs, NJ, 1978.

6. Abramowitz, M. \& Stegum, I., "Handbook of Mathematical Functions with Formulas, Graphs and Mathematical Tables," US Bureau of Standards, 1965, p. 920.

7. Dowson, D. and Hudson, J. D., "Thermo-Hydrodynamic Analysis of the Infinite Slider Bearing: Part $I$, The Plane-Inclined slider-Bearing. Part II, The Parallel-Surface Bearing," in Lubrication and Wear, May 23-25, 1963, (Inst. of Mech. Engrs., London, 1964), 34-51.

8. Hahn, E., and Kettleborough, C., "Pressure and Temperature in an Infinite slider Bearing of Arbitrary Profiles," ASME Inl. of Lubrication Technology, (1967), pp. 445-452.

9. Hamrock \& Dowson, "Ball Bearing Lubrication," Wiley, 1981, p. 142 .

10. Hunter, W. B. and Zienkiewicz, O. C., "Effect of Temperature Variations across the Lubricant Films in the Theory of Hydrodynamic Lubrication," Jnl. Mech. Engrg. Sci., Vol. 2, No. 1, 1960, pp. 52-58. 


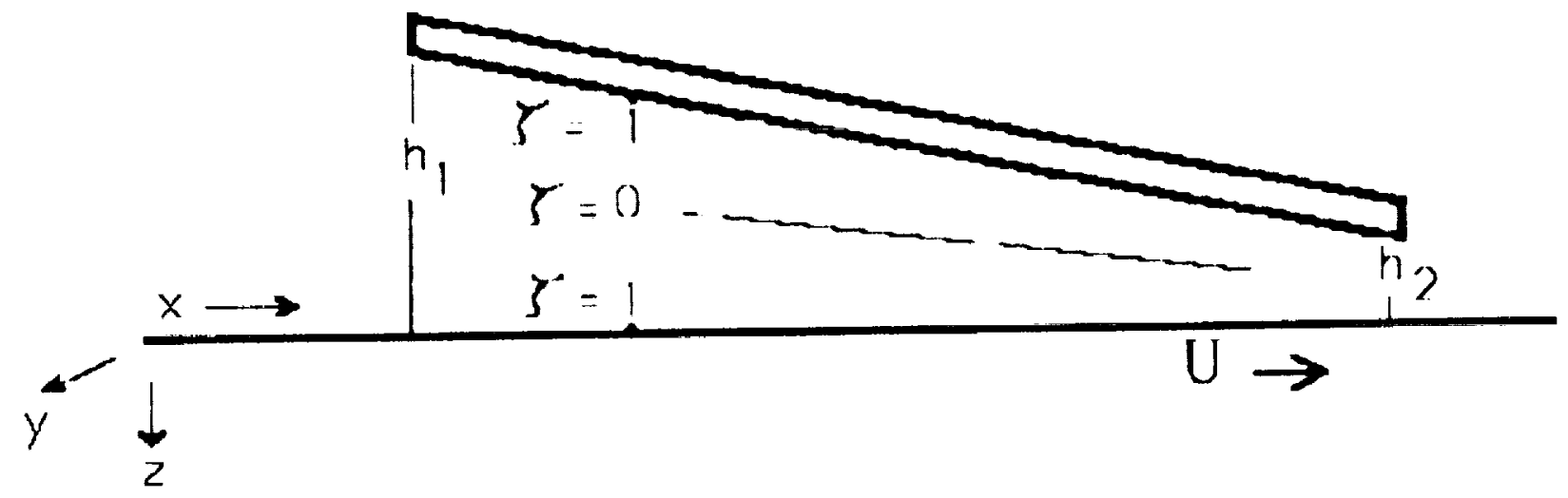

Figure 1 Schematic Diagram of Slider Bearing

(Note selection of coordinates) 


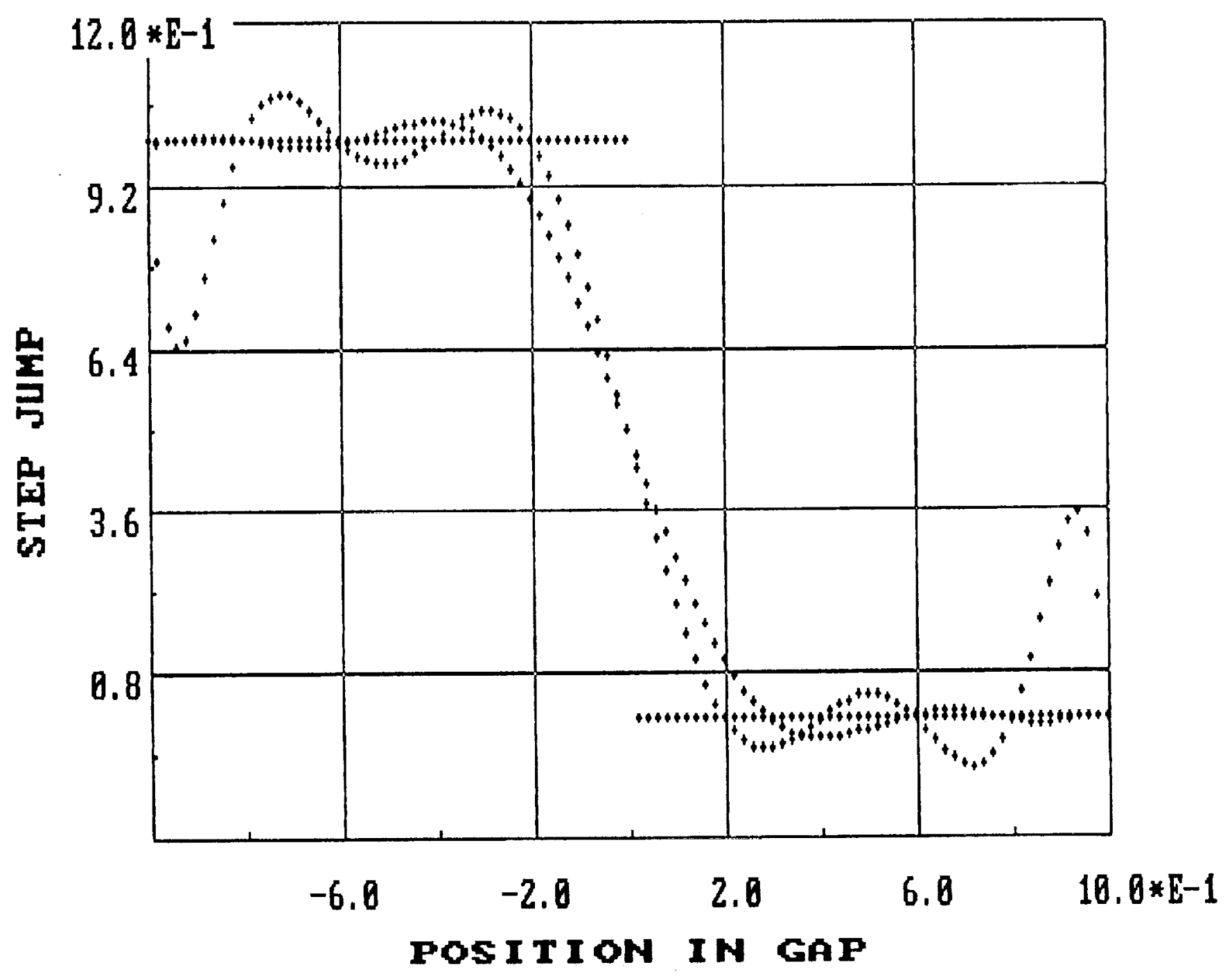

Eigure 2. Representation of $f(\zeta)=(1-\operatorname{sgn}(\zeta)) / 2$

by 11 pt. Equidistant \& Lobatto Interpolation 


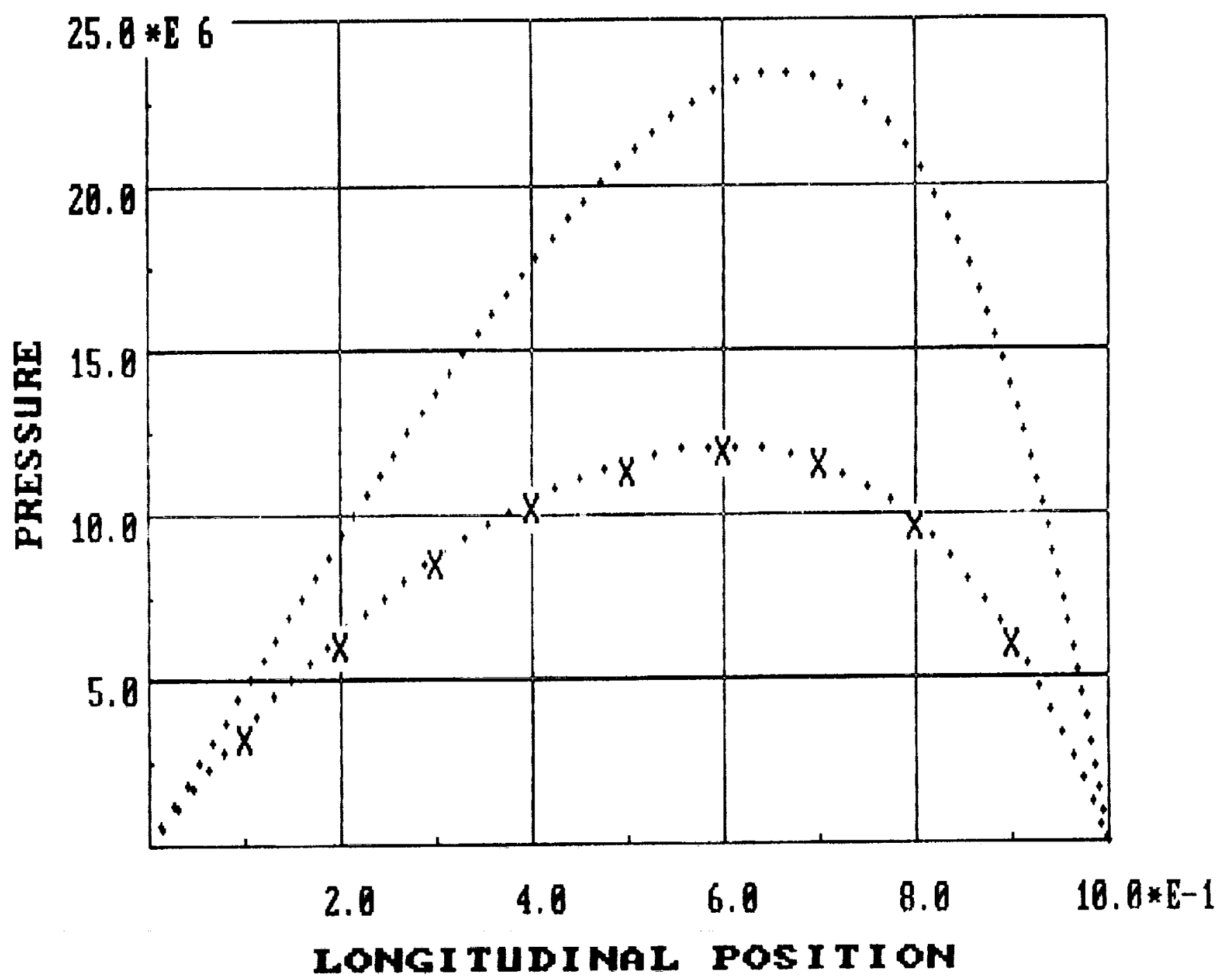

Figure 3. Pressure Profiles, Infinite-Width slider Beariny. $N=8(\ldots)$ vs. Dowson-Hudson $(X)$

Variabie Viscosity, $h_{1} / h_{2}=2$ 


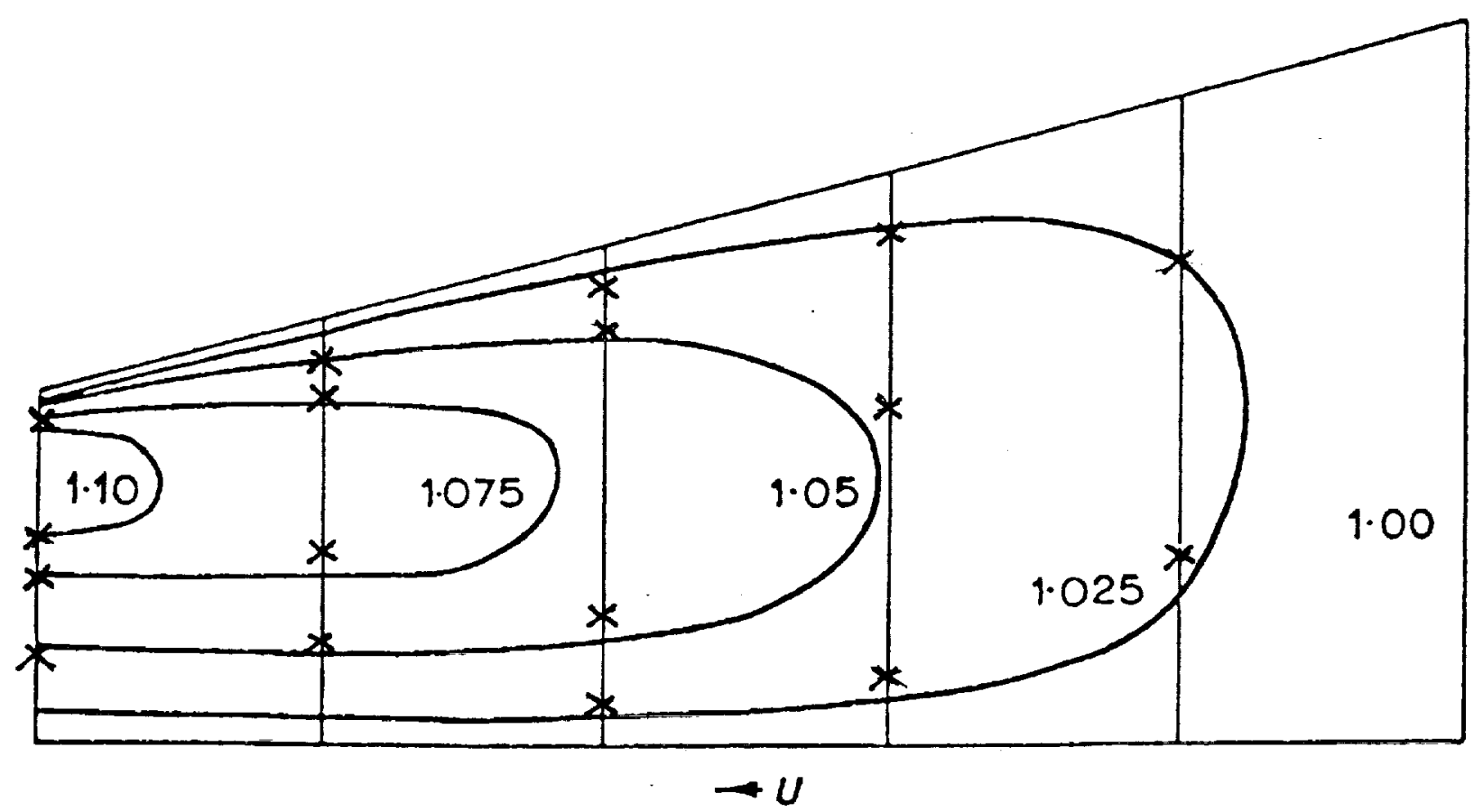

Figure 4. Temperature contours ( $T / 311)$ for Infinite-Width slider Bearing. Dowson-Hudson () vs. $N=8$ (X) Variable Viscosity, $h_{1} / h_{2}=2$ 


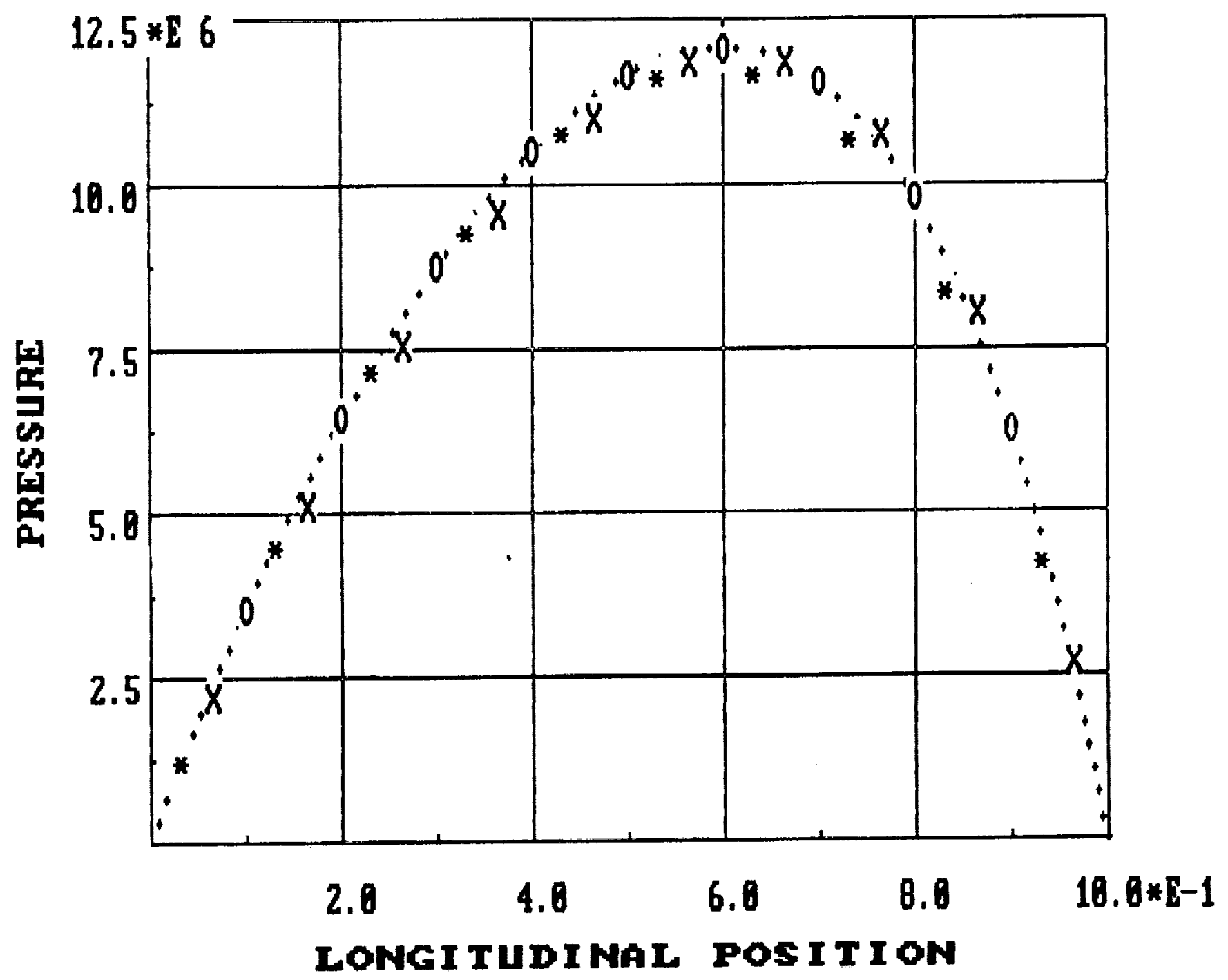

Figure 5. Convergence of Pressure Profiles with $\mathbf{N}$ Variable Viscosity, Infinite-Width slider, $h_{1} / h_{2}=2$ $N=8(\ldots) ; N=5(0) ; N=3(*) ; N=2(X)$ 


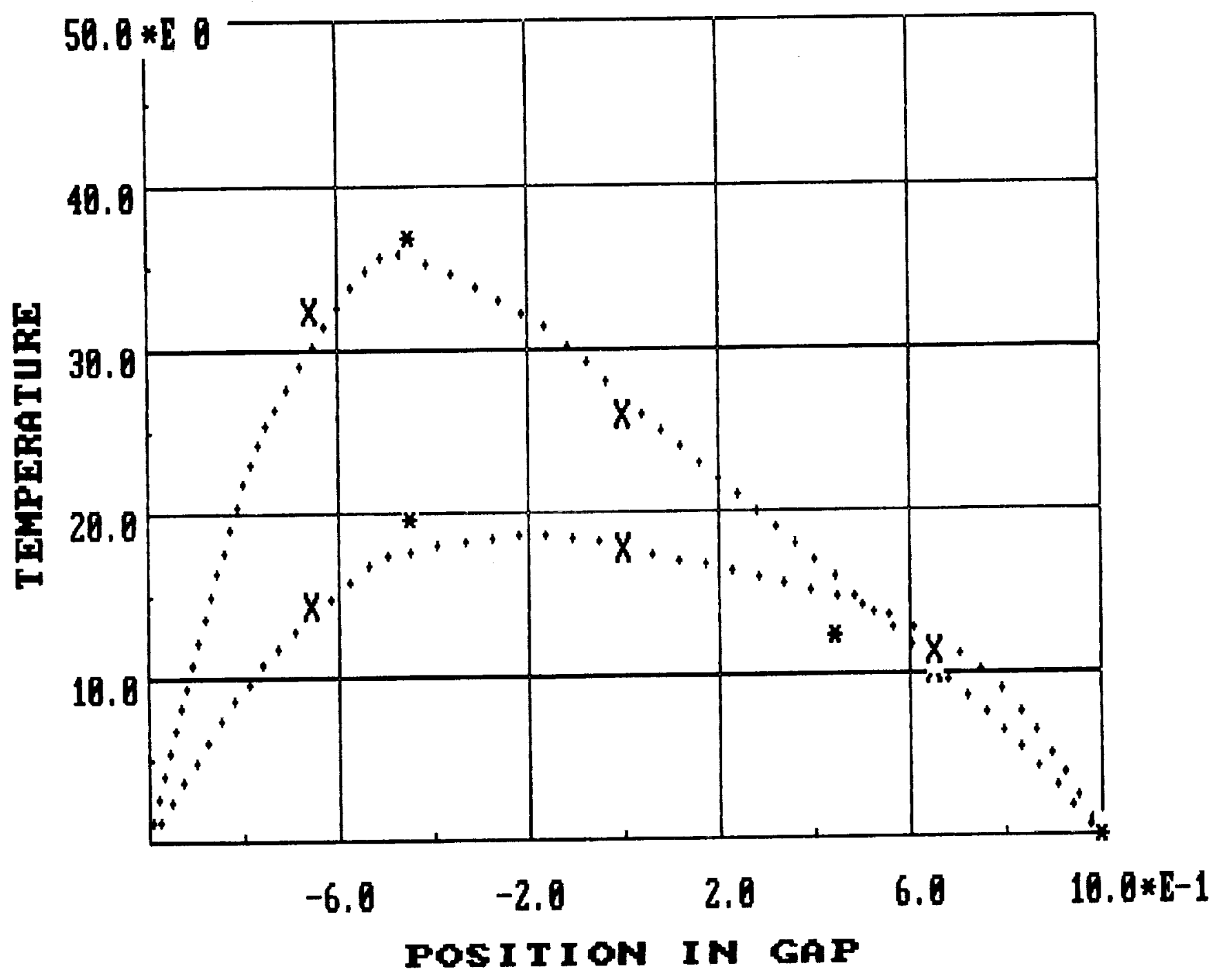

Figure 6. Temperature Profiles at Exit and Halfway Infinite-width slider, Variable Viscosity, $h_{1} / h_{2}=2$ $\mathrm{N}=8(\ldots) ; \mathrm{N}=3(*) ; \mathrm{N}=2(\mathrm{X})$ 


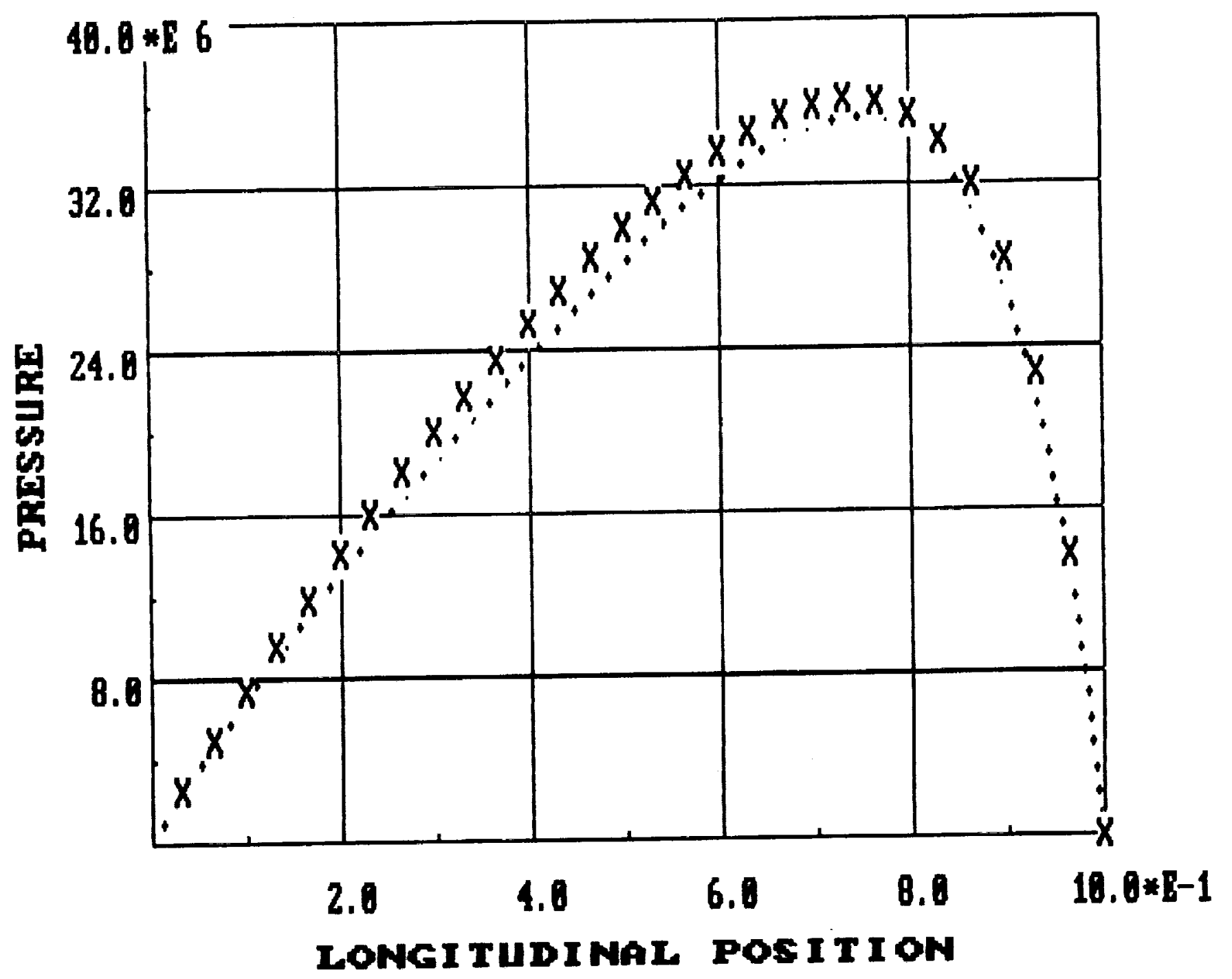

Figure 7. Pressure Profile for Infinite-width slider Variable viscosity, $h_{1} / h_{2}=4$

$\mathrm{N}=8(\ldots) ; \mathrm{N}=2(\mathrm{X})$ 


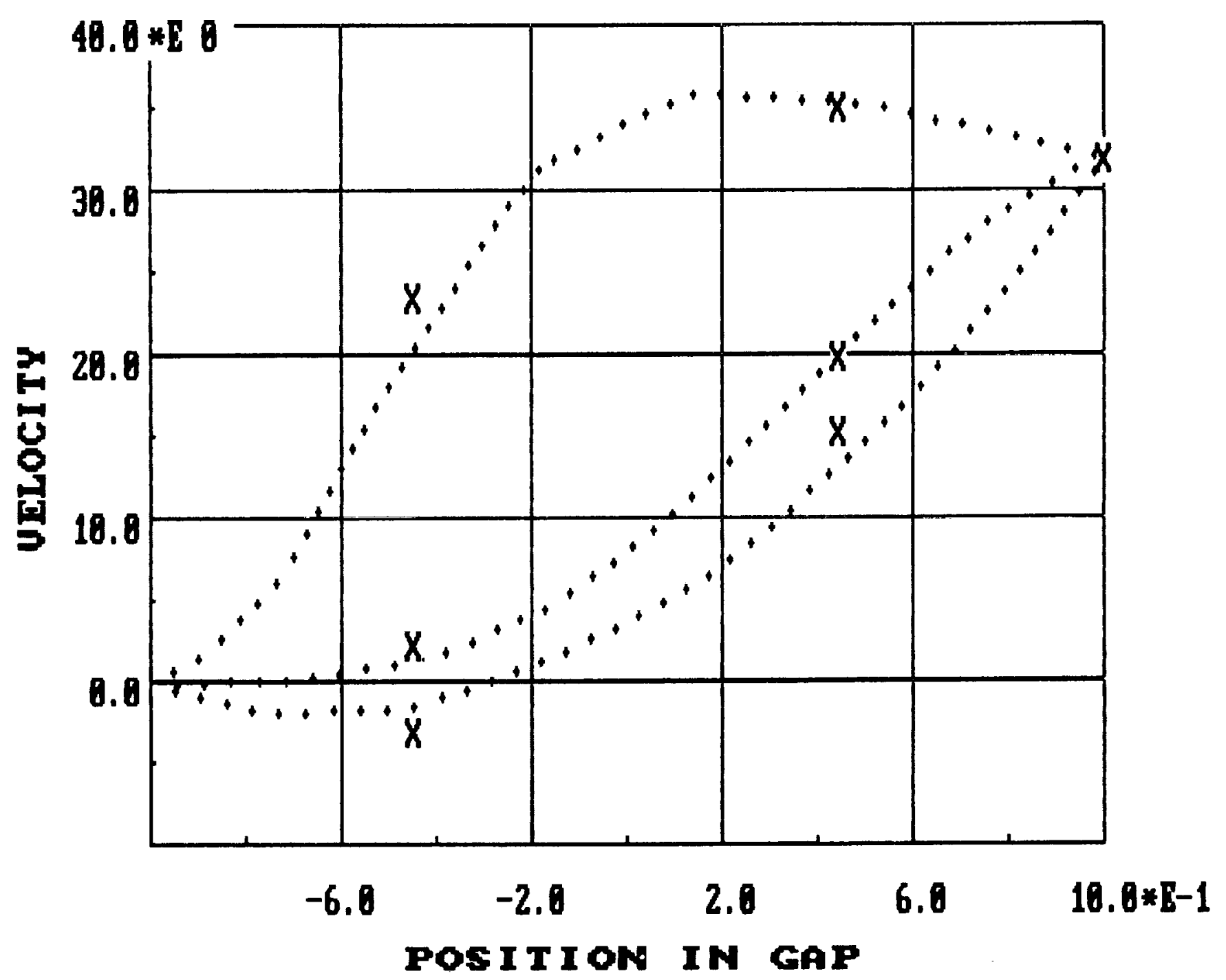

Figure 8. Velocity Profiles at Exit, Halfway \& Entrance
for Infinite-Width Slider, $h_{1} / h_{2}=4$ $\mathrm{N}=8(\ldots) ; \mathrm{N}=2(\mathrm{X})$ 


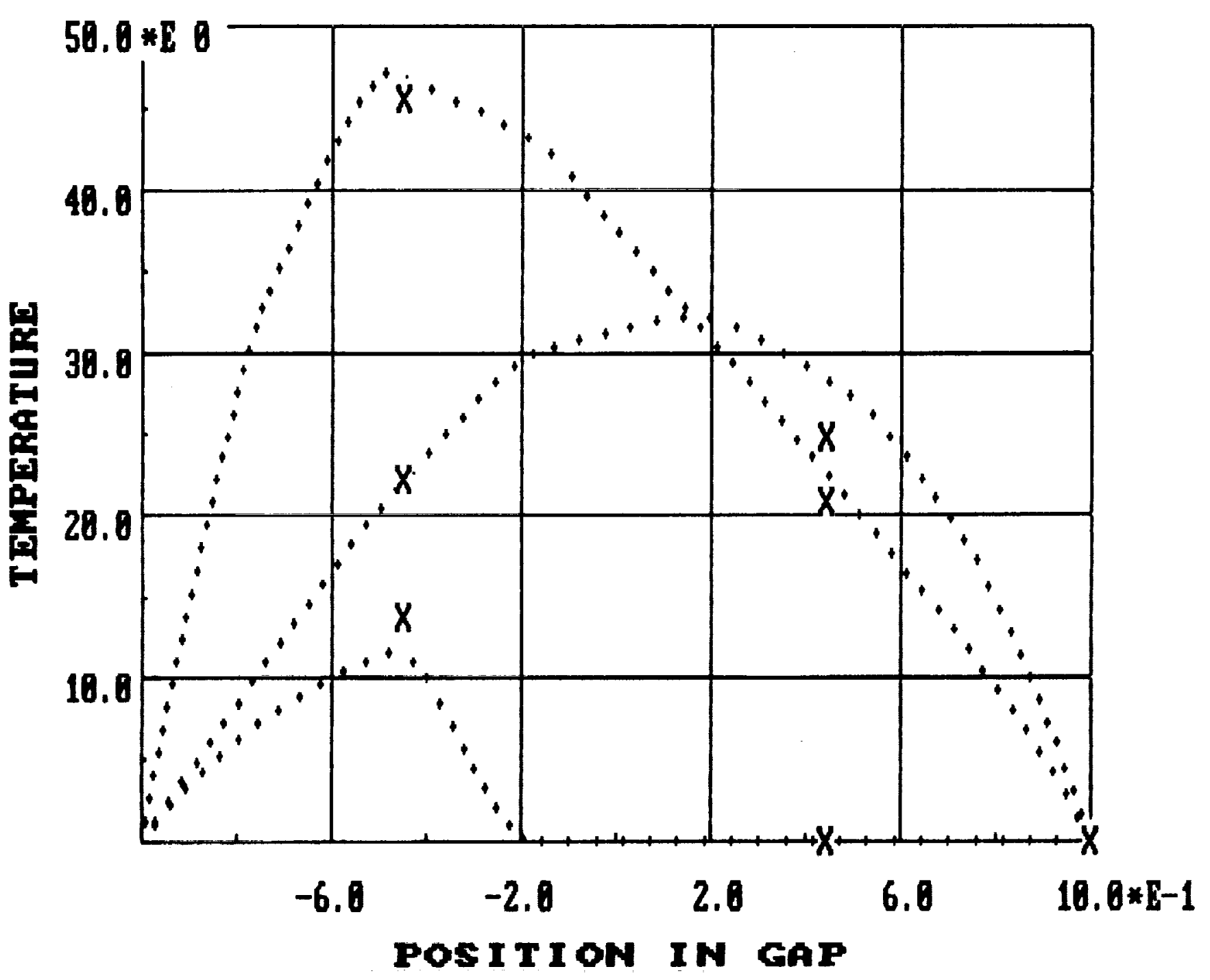

Figure 9. Temperature Profiles for Exit, Halfway \& Entrance Infinite-Width slider, $h_{1} / h_{2}=4$, variable viscosity $N=8(\ldots) ; N=2(x)$ 


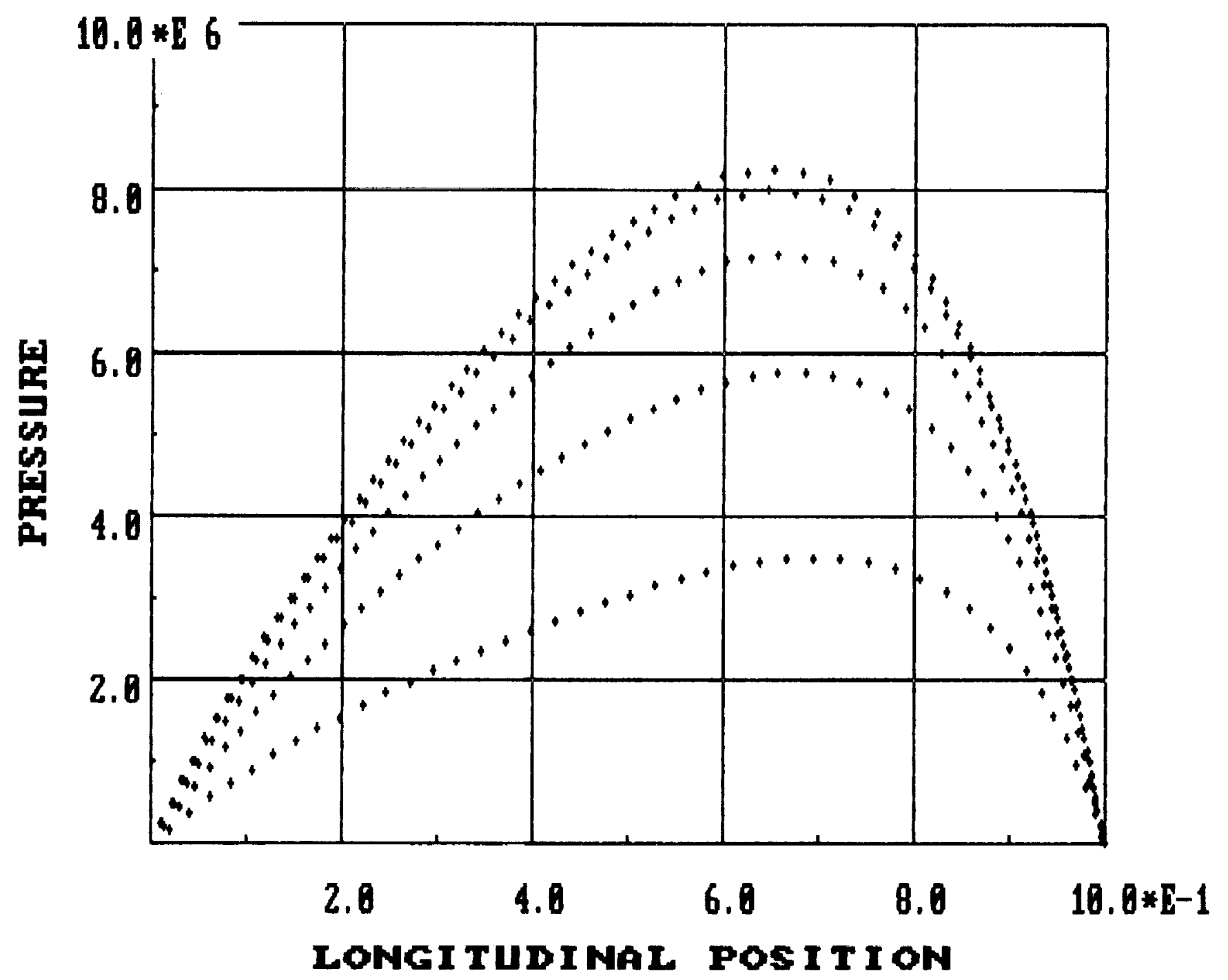

Figure 10. Pressure Profiles for Square Sidier Variatle Viscosity, $h_{1} / h_{2}=2$ $N=5$ 


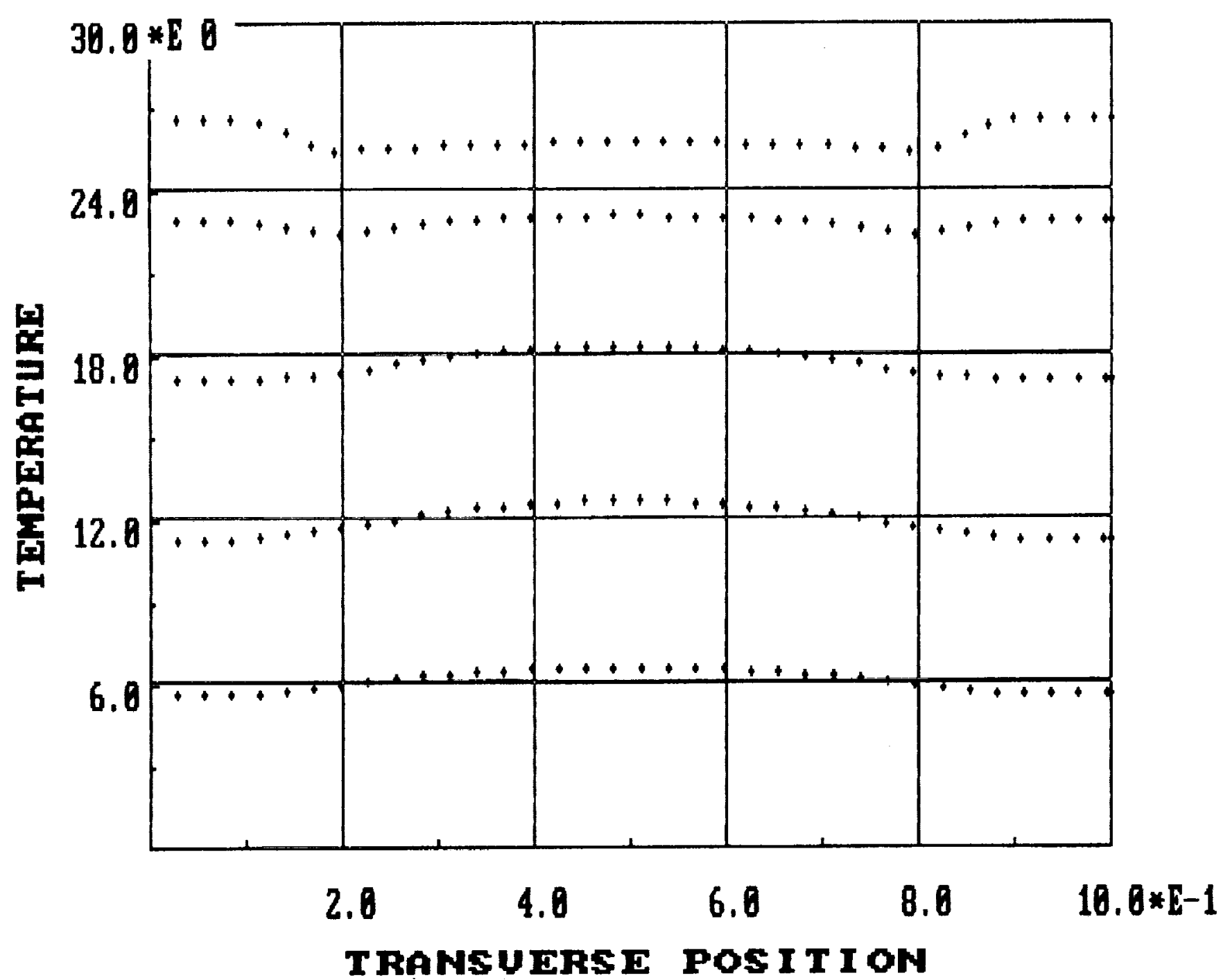

Figure 11. Center Temperature Protiles for square slider variable viscosity, $h_{1} / h_{2}$

$H=5$ 


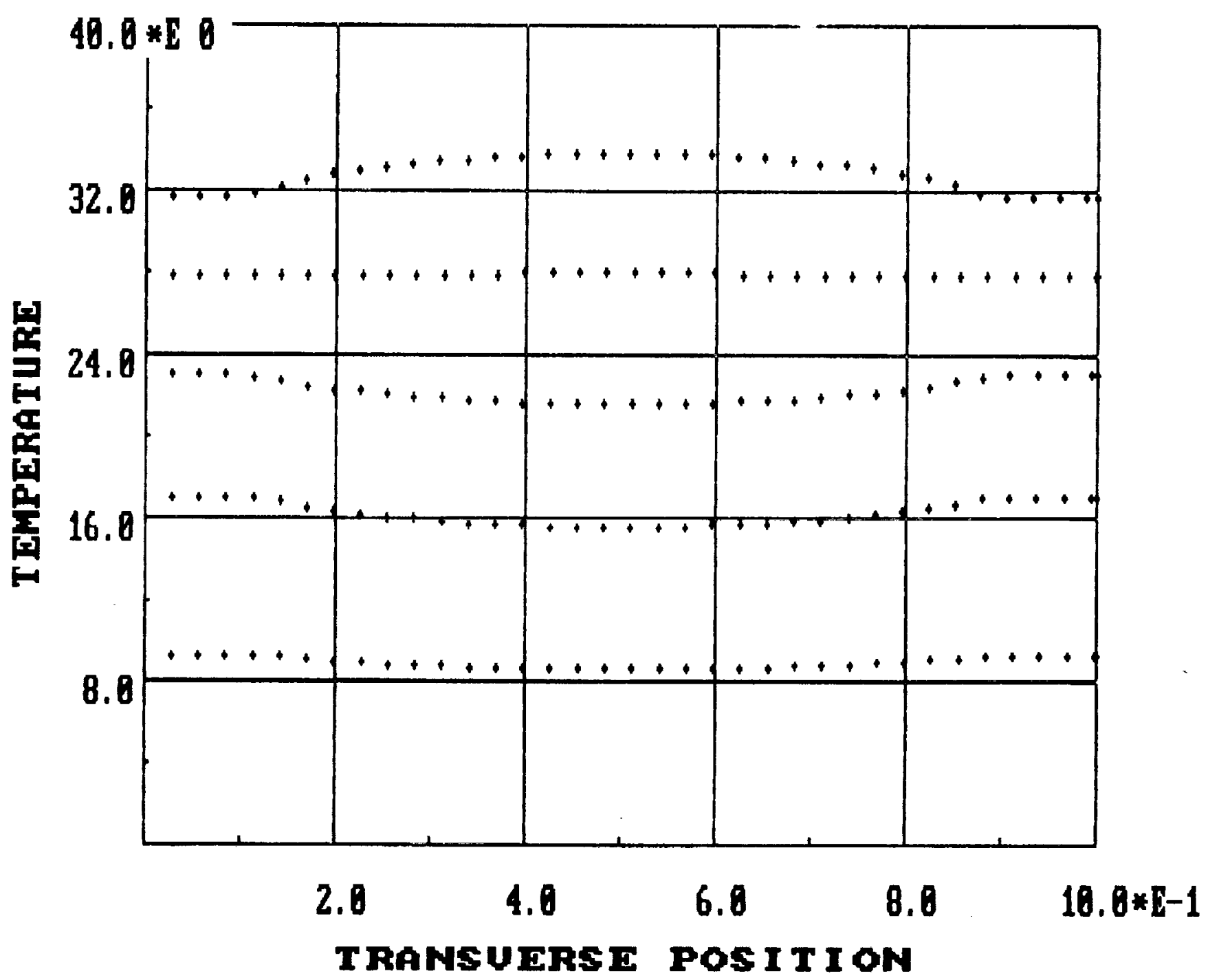

Figure 12. Temperature Profiles for square slider $\zeta=-.657$, variable viscosity, $h_{2} / h_{1}=2$ $N=5$ 


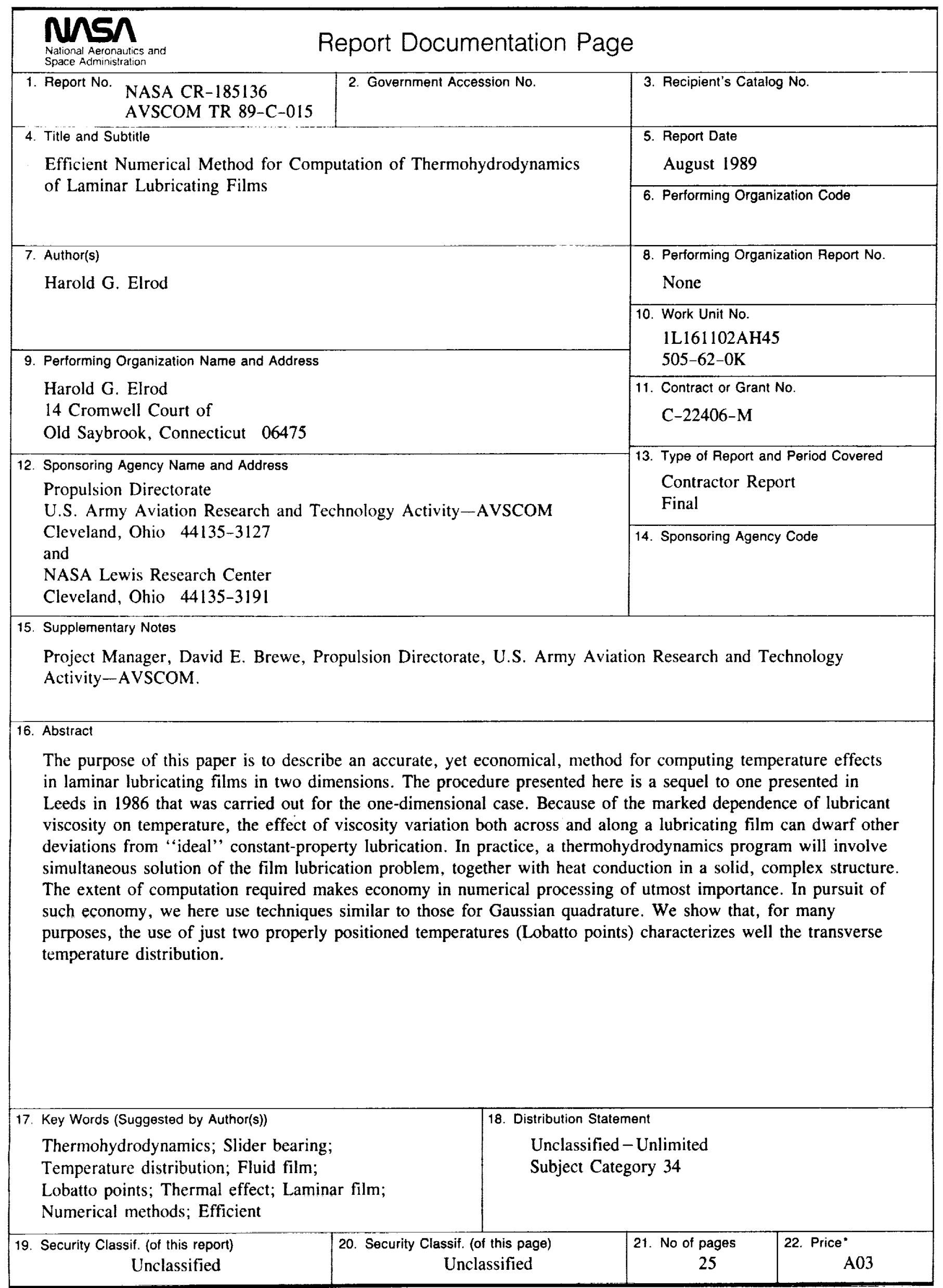

